\title{
RÖLLIT (AGROSTIS SPP.), RIKKARUOHOJAKO VAI HYÖTYKASVEJA?
}

\author{
K. Olsonen \\ Valtion siementarkastuslaitos, Helsinki.
}

Saapunut 11. 10. 1950.

Luonnonvaraisena kasvaa maassamme Hirtosen (4, p. 186-187) toimittaman "Suomen kasvion» mukaan viisi röllilajia. Niistä kaksi — pohjolan rölli (Agrostis borealis HN.) ja hoikka rölli (Agrostis clavata TRIN.) — on niin harvinaista, ettei niillä ole mitään käytännöllistä merkitystä sen enempää rikkaruohoina kuin muutenkaan. Jäljellä olevista sanoo VALLE (9, p. 768) kirjoituksessaan "Nurmikasvit»: "Yleisimmät lajit ovat rönsyrölli (Agrostis stolonifera L.), nurmirölli (Agrostis vulgaris Wiтн.) ja koiranrölli (Agrostis canina L.). Ulkomailla pidetään rönsyrölliä, joka on edellämainituista kasveista korkeakasvuisin ja lehtevin, varsin arvokkaana, pidetäänpä sen siementäkin kaupan. Nurmirölli on meillä yleisin ilmaantuen hoitamattomille, ravintoköyhille nurmille, mutta matalakasvuisena lajina on sen satoisuus pieni. Koiranrölli on erittäin kapealehtinen, rönsyilevä laji, ja hyvinkin arvoton, estäen arvokkaampien lajien ilmaantumista kosteaperäisillä mailla».

Grotenfelt (2, p. 507) ei mainitse röllejä ensinkään viljelyskasvien joukossa. Mutta laidunnurmikasvien yhteydessä hän sanoo: „Rönsyrölli (Agrotis stolonifera) on hieno, myöhäisenlainen ruoho, josta nautakarja ei pidä. Se tekee ruohoston tiheämmäksi ja sillä on lonkeroita, jotka useinkin ovat muiden parempien ruohojen tiellä. Hakamailla luetaan Agrostis-lajit rikkaruohoiksi, koska ne yleensä hyvin vähän lisäävät heinäsatoa». Ja luonnonniittyjen yhteydessä hän (2, p. 481) sanoo: „Rölliniittyjen heinät ovat tavallisesti lyhytkasvuisia ja koska ne tavallisesti niitetään liian myöhään, on niitä vaikea niittää terävällä ja hyvin asetetulla viikatteellakaan».

Olen kylvänyt itse omaan pihaani rönsyrölliä. Siitä kasvoi matala, tiheä, kutakuinkin yhtenäinen ruohikko. Kesillä 1945, 1946 ja 1947 asetin pienen aitauksen tällaisen rölliruohikon päälle ja kaksi lammasta sisään. Lampaat söivät kaiken muun ruohon, kuivaneet heinänkorretkin, mutta rölleihin ne eivät kajonneet. Koe- 
tin itsepäisesti pitää lampaat samassa paikassa useita päiviä. Ne vain sotkivat jaloillaan röllejä, mutta eivät syöneet niitä.

Mahdollista on, että röllit laihoilla mailla kelpaavat eläimille, koska CHARPENTIER (1, p. 507) sanoo kirjoituksessaan »Laidunkasvit» näin: „Arvokkaana lisänä laidunkasvillisuudessa ovat kuivemmilla mailla ja köyhemmillä maaperillä aronata ja nurmirölli». STEBLER ja VOLKART (7, p. 114) sanovat rönsyröllistä (Agrostis stolonifera L.) että se kosteilla ja märillä mailla, varsinkin viileillä seuduilla on hyvin arvokas heiniä. Se soveltuu yhtä hyvin niittonurmiin kuin laitumiin. Usein kun muut heinät kovan, sitkeän maan ja kylmien säitten takia häviävät täydellisesti, kasvaa rönsyrölli vielä hyvin. Se kasvaa tällöin tiheänä ja tukahduttaa rikkaruohot sekä varmentaa kohtalaisen sadon. Kuivilla mailla se ei menesty. Jos muut heinät kasvavat hyvin, jää hidaskasvuinen rölli muista jäljelle. Nurmiröllistä (Agrostis vulgaris Wilh. eli $A$. tenuis Siвth.) eivät nämä kirjoittajat mainitse mitään.

Mutta STRECKER (8, p. 116) kirjoitettuaan samaan tapaan rönsyröllistä, sanoo nurmiröllistä (Agrostis tenuis SIBTH.) (p. 119), että vaikkakin se vuoristoissa on arvokas heinä sekä niittonurmissa että laitumissa, on se muualla hyvinkin vähäarvoinen.

Koiranrölliä (Agrostis canina L). pidetään aivan yksimielisesti rikkaruohona.

Amerikan Yhdysvalloissa, Tyynen meren rannalla (Pacific Nortwest) viljellään nurmirölliä (Agrostis tenuis SIBTH.) kahtakin eri kantaa siemeneksi (5, p. 8). Amerikassa siis todennäköisesti viljellään nurmirölliä muutenkin. Mutta Euroopassa sen siementä ei tiettävästi ole ollut kaupan.

Rönsyröllin (Agrostis stolonifera L.) siemeniä sitävastoin on Euroopassakin kaupan. Niinpä on valtion siementarkastuslaitokseen saapunut tarkastettaviksi rönsyröllin siemennäytteitä, vaikkakaan ei joka vuosi. Niitten 30 vuoden kuluessa, joista on tilasto käytettävissä, on 23:na vuonna saapunut röllinäyte tai näytteitä. Neljänä vuonna on saapunut vain yksi näyte. Eniten on saapunut röllinäytteitä tarkastusvuonna 1938-1939. Silloin saapui 23 näytettä ja edustivat ne noin 7500 kilon suuruista röllinsiemenmäärää. Kaupassa olevat röllin siemenet on tuotettu Yhdysvalloista ja Tanskasta.

Edellisestä käynee selville, että ainoa röllilaji, josta voidaan sanoa, että sitä todella viljellään Euroopassakin, on rönsyrölli (Agrostis stolonifera L.). Sen siementä on kaupan ja sitä myös kylvetään. Ja sitä viljellään varsinaisesti ulkomailla ja sielläkin vain kosteilla, veden vaivaamilla mailla, joissa arvokkaammat heinät eivät menesty. Suomessa sen viljely rajoittuu vain leikki- ja urheilukenttiin, ehkä jossain määrin laidunmaihin. Nurmirölli (Agrostis tenuis SIBTH.) on kuivien maitten kasvi. Siitä sanotaan olevan hyötyä vuoristoissa ja kuivilla heikkokasvuisilla laitumilla. Hyvillä mailla kummatkin röllit ovat vähäarvoisia. Koiranrölliä (Agrostis canina L.) pidetään aivan yleisesti kaikkialla rikkaruohona. Ja jos pidämme rikkaruohoina kaikkia niitä kasveja, jotka tuppautuvat viljelyksille viljelijäin tahtomatta, on myös rönsy -ja nurmiröllejä pidettävä rikkaruohoina, varsinkin timoteija apilanurmissa.

Rönsyröllin ja nurmiröllin siemenet ovat kaksihelpeisiä. Rönsyröllin ulkohelve on vihneetön (4). Mutta jos siinä sattuisi olemaan vihne, niin se on lyhyt, suora 
tai puolipolvinen tai ainoastaan piikki sekä kiinni helpeen kärkipäässä (5, p. 8). Nurmiröllin siemenet ovat tavallisesti vihneettömiä (4, p. 186). Kun niissä on vihne, niin se saattaa olla polvinen, kierteinen tai suora ja kiinni helpeen tyvessä. Kun niissä on vain vihneen paikka näkyvissä, mutta ei vihnettä, niin se voi olla helpeen puolivälissä tai likempänä helpeen kärkeä. Rönsyröllin ulkohelve on lakankiiltoinen, nurmiröllin ulkohelve on sitävastoin hopeanhohtoinen tai himmeähkö. Useissa tapauksissa tämä helpeen erilainen kiilto on näitten eri röllin siementen ainoa erottava tuntomerkki (5, p. 8).

Koiranröllin siemenet ovat yksihelpeisiä. Helpeen tyvestä lähtee tavallisesti kaleita hieman pitempi vihne (4, p. 187). Mutta ne eivät ole aina vihneellisiä.

Silloin kun koiranröllin siemenessä on helve jäljellä, voidaan se siis erottaa rönsyja nurmiröllin siemenistä, mutta kaikki kuoriutuneet röllin siemenet ovat niin toistensa näköisiä, että niitten erottaminen toisistaan on mahdotonta. Koiranröllin siementen ainoa helve ympäröi niin täydellisesti koko siemenen, että senkin toteaminen yksihelpeiseksi kaipaa tottumusta ja hyvää suurennusta.

Eri röllilajien toisistaan erottaminen on siis aikaa viepää. Sitä tehtäessä on usein binokularinen mikroskooppi tarpeellinen. Ja voivat sen tehdä ainoastaan röllin siementen erottamiseen erikoisesti harjaantuneet henkilöt. Ja tällöinkin saattaa rönsyröllin ja nurmiröllin siementen erottaminen toisistaan olla mahdotonta tai ainakin epävarmaa, varsinkin silloin, kun siemen on ennättänyt kadottaa kiiltonsa .

Toimintakautensa ensimmäisten kolmenkymmenen vuoden aikana on valtion siementarkastuslaitoksessa kaikki röllien siemenet liitetty rikkaruohojen siemeniin. Kun syksyllä 1949 vietiin maastamme timotein siemeniä Yhdysvaltoihin, ja siellä röllejä pidetään hyötykasveina (8), punnittiin täälläkin vientitimoteista röllin siemenet erikseen hyötykasveina marraskuun alusta 1949.

Aikaisemmin jo 1946 siementarkastuslaitokselle lähettämässä kirjeessä »S i em e n k a p p i a it t e n Y h d is t y s» ry. ehdotti, että maassammekin yhdenmukaisuuden takia pidettäisiin röllin siemeniä hyötykasvien siemeninä. Saadaksemme selville, kuinka yleisesti ja kuinka paljon timoteinsiemennäytteissä on röllin siemeniä, erotettiin ne tästä lähtien timotein puhtausmääritysten yhteydessä ja punnittiin. Punnitustulos merkittiin puhtauslomakkeisiin vain laitoksen omaa tilastotarvetta varten. Senjälkeen punnittiin röllin siemenet yhdessä muitten rikkaruohojen kanssa. Näin saadun tilaston tulokset näkyvät seuraavasta taulukosta:

timoteinsiemennäytteissä

$\begin{array}{ccccc}\text { tarkastusvuosina } & \begin{array}{c}\text { oli rölliä } \\ \%\end{array} & \begin{array}{c}\text { eniten rölliä } \\ \%\end{array} & \begin{array}{c}\text { keskimäärin rölliä } \\ \%\end{array} & \text { näyteluku } \\ 1946-1947 & 78 & 22.1 & 0.5 & 529 \\ 1947-1948 & 83 & 5.0 & 0.4 & 596 \\ 1948-1949 & 94.5 & 2.9 & 0.4 & 109\end{array}$

Useammalta vuodelta ei tilastoa vielä ole, mutta näistäkin numeroista jo näkee, että röllin siemeniä saattaa eräinä vuosina olla melkeinpä joka näytteessä $(94.5 \%)$. Niitä saattaa joskus olla hyvinkin paljon (22\%). Niitten keskimäärä on kuitenkin eri vuosina ollut jokseenkin sama. 
Ja saadaksemme varmemmin ja tarkemmin selville kuin yksinomaan vain siemeniä katsomalla on mahdollista määrittää, ovatko kotimaisissa timotein siemenissä olevat röllin siemenet mahdollisesti rönsyröllin (Agrostis stolonifera L.) siemeniä, jolloin niitä voitaisiin pitää hyötykasveihin kuuluvina, vai ovatko ne muitten röllien siemeniä ja siinä tapauksessa rikkaruohoja, pyydettiin kesällä 1949 siemenkonsulentteja eri puolilta maata lähettämään heinäpelloissa kasvavia röllejä juurineen siementarkastuslaitokseen.

Syksynmittaan saapui siementarkastuslaitokseen 37 tällaista röllinäytettä. Kunkin näytteen laji määritettiin alustavasti siementarkastuslaitoksessa. Sen jälkeen toht. HirtoneN vielä tarkisti nämä määritykset. Kaksi näytettä oli niin huonoa, ettei niitten lajia voitu määrittää. Kaikkiaan saatiin siis 35:stä näytteestä selvyys, mitä röllilajia ne olivat. Ainoastaan neljä näytettä oli rönsyrölliä (Agrostis stolonifera L.), eli sellaista rölliä, jota voitaisiin pitää viljelyskasvina. Valtavasti suurin osa, 27 näytettä oli nurmirölliä (Agrostis temuis Siвтн.), jota ei Euroopassa varsinaisesti viljellä, vaikkakin siitä erikoisolosuhteissa, esim. vuoristoissa STRECKER̉in (8, p. 119) ilmoituksen mukaan voi olla hyötyä. Ojitetuilla heinäpelloilla sitä on pidettävä rikkaruohona. Loput neljä näytettä olivat koiranrölliä (Agrostis canina L.). Ja siitä pidetään riidattomasti kaikkialla rikkaruohona. Yhden nurmiröllinäytteen joukossa oli sitäpaitsi jonkinverran koiranrölliä. On siis ollut täysin perusteltua, että maassamme röllin siemeniä on timotein siementen joukossa pidetty rikkaruohojen siemeninä.

Maahamme on viime vuosina tuotu ja täältä on myöskin viety timotein siemeniä. Ja kuten edellä jo on selvitetty, ulkomailla viljelläänkin jossain määrin rönsyrölliä. Kun rönsyröllin siemeniä on vaikea erottaa nurmiröllin siemenistä ja koiranröllin siementen erottaminenkin muista röllien siemenistä on aikaa viepää ja senkin voivat tehdä ainoastaan röllien siementen erottamiseen erikoisesti harjaantuneet henkilöt, pidetään monessa maassa kaikkia röllin siemeniä erotuksetta hyötykasveina. Kuten edellä mainittiin Siemenkauppiaitten yhdistys ehdotti jo kesällä 1946, että maassammekin yhdenmukaisuuden takia pidettäisiin röllien siemeniä hyötykasvien siemeninä.

V. 1949 tiedusteli Keskusosuusliike Hankkija eräiltä Europan siementarkastuslaitoksilta, pidetäänkö niissä röllejä rikkaruohoina vai hyötykasveina. Ruotsin ja Tanskan siementarkastuslaitokset ilmoittavat pitävänsä koiranröllin (Agrostis canina L). siemeniä rikkaruohoina, muita kaikkia hyötykasveina. Ruotsin siementarkastuslaitos ilmoittaa vielä, että amerikkalaisissa rönsyröllin (Agrostis stolonifera L.) siemenissä esiintyviä Agrostis Ellotiana- ja Agrostis hiemalis-röllien siemeniä he pitävät rikkaruohoina. Norjan, Sveitsin, Hollannin ja Englannin siementarkastuslaitokset pitävät kaikkia röllejä erotuksetta hyötykasveina.

Kaikkialla ei kuitenkaan menetellä näin. Niinpä Jenan siementarkastuslaitoksen johtaja EGGEBRECHT (3, p. 68) luettelee, mitä kasveja rehunurmissa on pidettävä hyötykasveina ja mitä rikkaruohoina. Hänen luettelonsa mukaan rönsyrölli (Agrostis stolonifera L.) on hyötykasvi, mutta nurmirölli (Agrostis temuis SiBTH.) on rikkaruoho. 
Ja saadaksemme vielä useammalta taholta tietoomme, minä eri maissa eri röllejä pidetään, tiedusteltiin siementarkastuslaitoksen puolesta tätä asiaa v. 1950 useasta Europan siementarkastuslaitoksesta.

Vastauksessaan Münchenin siementarkastuslaitoksen johtaja MERL ilmoittaa, että hänen laitoksellaan, samaten kuin koko Saksassa noudatetaan edellä mainitsemiani EGGEBRECHTin 1949 julkaisemia ohjeita. Niitten mukaisesti he siis pitävät rönsyrölliä hyötykasvina, mutta nurmirölliä rikkaruohona. Rikkaruohoina hän ilmoittaa myöskin pidettävän koiranrölliä. Lisäksi hän mainitsee, että siellä kaupassa oleva niinkutsuttu eteläsaksalainen röllinsiemen on luonnonvaraisista rölleistä kerättyä siementä, jossa on sekaisin rönsy-, nurmi- ja koiranröllin siemeniä. Tällaista siementä tarkastettaessa pidetään toisistaan erottamatta kaikkia röllin siemeniä hyötykasveina, olkoot ne minkä röllin siemeniä tahansa. Näin menetellään, koska tällaisella siemenellä ei ole mitään maataloudellista merkitystä, vaan kylvetään sitä yksinomaan puistoihin ja urheilukenttiin.

Budapestin siementarkastuslaitoksen johtaja ScHERMANN ilmoittaa, että Unkarissa pidetään rönsyrölliä (Agrostis stolonifera L.) hyötykasvina, mutta nurmirölliä (Agrostis temuis Sibth.) ja koiranrölliä (Agrostis canina L.) rikkaruohoina.

Wienistä ilmoittaa GERM, että Itävallassa, samaten kuin VoIsEnAT Parisista, että Ranskassa pidetään kaikkia röllilajeja erotuksetta hyötykasveina.

Koska maamme timoteinsiemenkauppa viime vuosina on tullut osaksi myös kansainväliseksi ja koska monessa muussa maassa, kuten edellä on selvitetty, röllejä pidetään hyötykasveina, vaikkei niitä kaikkia suorastaan viljellä, punnittiin täälläkin, kuten jo mainittiin, vientitimoteista röllien siemenet erikseen muista rikkaruohoista ja merkittiin tarkastustodistuksiin hyötykasveina marraskuun alusta 1949. Ja joulukuun alusta 1949 on yhdenmukaisuuden takia siementarkastuslaitoksessa kaikista näytteistä ilman erotusta röllien siemenet punnittu erikseen hyötykasveina.

Mutta röllit ovat silti vielä röllejä. Niitten viljelysarvo ei silti ole muuttunut, vaikka ne siementen tarkastustodistuksissa tätä nykyä esiintyvätkin erikseen. Ne ovat yhä vielä sellaisia kasveja, jotka tuppautuvat viljelyksille viljelijäin tahtomatta. Ja viljelijät ottakoot sen huomioon. Nehän voidaan lajittelukoneilla verraten tarkkaan poistaa timotein siemenistä.

Siementavarain vähimpiä vaatimuksia määrättäessä myyntikaudeksi 1949-1950 tämä seikka on jo otettu huomioon. Sillä kun röllien siemeniä ei enää ole rikkaruohojen siementen joukossa ja niitä on tilastomme mukaan ollut timotein siementen joukossa keskimäärin lähes puoli prosenttia, on vähimpiä vaatimuksia määrättäessä timotein siemenissä sallittua korkeinta rikkaruohojen siementen määrää alennettu puolella prosentilla.

Aikaisemmin sai timotein siementen joukossa olla rikkaruohojen siemeniä korkeintaan $1.5 \%$, tätä nykyä niitä saa olla ainoastaan $1 \%$. Vaikka siis röllit erotetaankin rikkaruohoista ja merkitään hyötykasveiksi, ollaan rikkaruohojen siemeniin nähden yhtä ankaria kuin ennenkin. 


\section{KIRJALLISUUTTA.}

(1) Charpentier, A., 1929. Maatalouden tietosanakirja II. Helsinki.

(2) Grotenfelt, Gösta, 1922. Suomalainen peltokasviviljelys. II. Helsinki.

(3) Eggebrecht, Heinrich, 1949. Methodenbuch, Band V. Die Untersuchung von Saatgut. Radebeul und Berlin 1949.

(4) Hitonen, Ilmari, 1933. Suomen Kasvio. Helsinki.

(5) Musil, Albina F. 1950. Distinguishing Features of Seeds of Certain Crops Comparatively New in American Agriculture. IX International Seed Testing Congress, May 1950, Washington, D. C.

(6) Rules and Regulations Under the Federal Seed Act. 1940 \$ 304.

(7) Stebler, F. G. ja Volkart A. 1913. Die besten Futterpflanzen. Bern

(8) Strecker, W. 1921. Erkennen und Bestimmen der Wiesengräser. Berlin.

(9) Valle, Otto, 1929. Maa ja Metsä. Kasvituotanto, 2, Nurmikasvit. Porvoo.

\section{REFERAT.}

\section{STRAUSSGRÄSER (AGROSTIS SPP.) UNKRÄUTER ODER NUTZPFLANZEN?}

\section{K. OLSONEN}

\section{Der Staatliche Samenkontrollanstalt, Helsinki.}

Die Partien finnischer Timotheesamen enthalten ungefähr ein halbes Prozent Straussgrassamen (Agrostis spp). Diese sind vor allem Samen des Gemeinen Straussgrases (A. tenuis Sibth), seltener kommen Samen des Hunds-Straussgrases (A. canina L.) vor und noch seltener Samen des weissen Straussgrases oder Fioringrases (A. stolonifera L.). Während der ersten dreissig Jahre wurden in der Staatlichen Samenkontrollanstalt alle Straussgrassamen als Unkrautsamen betrachtet. Als im Herbst 1949 Timotheesamen nach U.S.A. ausgeführt wurden, und Straussgras wird in U.S.A. den Nutzpflanzen zugeordnet, wurden auch hier seit Anfang November 1949 die Straussgrassamen getrennt vom Exporttimothee als Kulturpflanzen gewogen. Und seit Anfang Dezember 1949 wurden in der Staatlichen Samenkontrollanstalt Finnlands bei allen Proben ohne Ausnahme alle Straussgrassamen als Kulturpflanzen gesondert gewogen.

Aber Straussgräser sind trotzdem eben Straussgräser. Ihr Kulturwert hat sich trotzdem nicht verändert. Straussgrasarten sind solche Pflanzen, die sich gegen der Wunsch des Bauern in den Kulturen ausbreiten.

Beim Feststellen der Mindestanforderungen an Saatgut in der Verkaufsperiode 1949-1950 ist dieser Umstand bereits beachtet worden. Denn da es unter den Unkrautsamen keine Straussgrassamen mehr gibt und diese nach unserer Statistik durchschnittlich ein halbes \% vom Timotheesamen ausgemacht haben, ist beim Feststellen der Mindestanforderungen an den Timothee gestattet worden, den höchsten Gehalt der Unkrautsamen um ein halbes Prozent zu senken. Obgleich also das Straussgras vom Unkraut unterschieden und als Kulturpflanze bezeichnet wird, ist man hinsichtlich der Unkrautsamen ebenso streng wie früher 